\title{
Burden of Lung Cancer and Associated Risk Factors in Africa by Region
}

Alexandra Urman', Sowmya Josyula², Alex Rosenberg', David Lounsbury², Thomas Rohan ${ }^{2}$, and H. Dean Hosgood ${ }^{2 *}$

${ }^{1}$ Department of Oncology, Montefiore Medical Center, Bronx, NY, USA

${ }^{2}$ Department of Epidemiology and Population Health, Albert Einstein College of Medicine, Bronx, NY, USA

\begin{abstract}
Purpose: Lung cancer is the most common incident cancer worldwide, accounting for $13 \%$ of all cancers. With decreasing burden of infectious diseases and increasing life expectancy in Africa, this study sought to identify risk factors for lung cancer and suggest mitigation strategies for implementation.
\end{abstract}

Methods: Lung cancer incidence rates for the different regions of Africa were determined using data from Globocan (2012) and risk factors were determined through an extensive literature review.

Results: Males have higher lung cancer incidence rates than females in all regions of Africa. The combined male and female incidence rates for Middle, Eastern, and Western Africa, were lower than those observed in Southern and Northern Africa. The incidence rates of lung cancer were highest in South African Republic $(18.5$ per 100,000) followed by France La Reunion (17.6 per 100,000). Smoking was the most common risk factor studied followed by occupational/environmental risk factors, and infectious agents (e.g., HIV). A limited number of candidate gene studies have evaluated the genetic susceptibility to lung cancer in these populations. Not all regions of Africa have had research studies published on the etiologic risk factors of lung cancer.

Conclusions: The lung cancer incidence rates are lower in Africa compared to incidence rates elsewhere, possibly due to a true lack of cases or detection biases. There is limited data on lung cancer (particularly risk factors) in Africa, especially Central, Eastern and Western Africa, pointing out the need for more research, prior to considering targeted prevention policies.

Keywords: Lung cancer; Africa; Incidence rates; Smoking; Asbestos

\section{Introduction}

Lung cancer is the most common cancer worldwide, accounting for $13 \%$ of all incident cancers. It is also the leading cause of cancer deaths, accounting for about 1.4 million deaths in 2008 (18.2\% of the total) $[1,2]$. The reported lung cancer incidence rates are higher in the United States and European countries and lower in Africa, Central and South America, and Asia [3]. Temporal analyses reveal that significant reductions in lung cancer mortality have been observed in developed countries from increased awareness of the harmful effects of smoking and asbestos [3]. In contrast, lung cancer incidence and mortality rates have increased in some low and medium resourced countries [4]. These regional differences may be attributed to an increase in lung cancer risk factors and/or exposures and an aging population. Additionally, variations in risk may be ascribed to better treatment for and prevention of infectious diseases [5].

Improvement in health care delivery systems, such as those in Middle, Eastern and North African (MENA), have resulted in an increase in the elderly population in Africa [6]. The number of people aged 65 or more in Africa is expected to quadruple by 2050 to 193 million, or $10 \%$ of the population [6]. As life expectancy continues to increase throughout the African continent, the burden of cancer is likely to increase. Given that an estimated 32,640 new lung cancer cases will be seen in Africa in 2015 [7], it is important to assess and understand the current knowledge of the lung cancer burden and associated risk factors in the distinct regions of Africa.

\section{Methods}

We assessed the current state of knowledge pertaining to the lung cancer burden and known risk factors for the 5 African regions: Northern, Southern, Eastern, Western, and Middle Africa. We used the United Nations classification structure to define the African regions. Northern Africa is comprised of Algeria, Egypt, Libya, Morocco, Sudan, Tunisia, and Western Sahara. Eastern Africa is comprised of Burundi,
Comoros, Djibouti, Eritrea, Ethiopia, Kenya, La Reunion (France), Madagascar, Malawi, Mauritius, Mozambique, Rwanda, Somalia, South Sudan, Tanzania, Uganda, Zambia, and Zimbabwe. Middle Africa is comprised of Angola, Cameroon, Central African Republic, Chad, Democratic Republic of Congo, Republic of Congo, Equatorial Guinea, and Gabon. Southern Africa is comprised of Botswana, Lesotho, Namibia, South African Republic, and Swaziland. Western Africa is comprised of Benin, Burkina Faso, Cape Verde, Cote d'Ivoire, Gambia, Ghana, Guinea-Bissau, Guinea, Liberia, Mali, Mauritania, Niger, Nigeria, Senegal, Sierra Leone, and Togo.

To evaluate lung cancer incidence and mortality in Africa, the Globocan (2012) (http://globocan.iarc.fr/) database was used. Globocan [7] is a project that provides contemporary model-based estimates of incidence, mortality and prevalence from major types of cancer, at a national level, for 184 countries. The data is presented for 2012 and includes 1-, 3- and 5-year prevalences for the adult population (ages 15 and over). The methods used by Globocan [7] for the estimation of rates are country specific and the quality of the estimation depends upon the quality and on the amount of the information available for each country. Globocan [7] therefore created an alphanumeric scoring system which independently describes the availability of incidence and mortality data for each country. The combined score is presented together with the estimates for each country and can be found at the following web address: http://globocan.iarc.fr/Pages/DataSource_and_ methods.aspx. We extracted data from this database, which included

*Corresponding author: Dean Hosgood, Professor, Department of Epidemiology and Population Health, Albert Einstein College of Medicine, Division of Epidemiology 1300 Morris Park Ave., Belfer Building Room 1309, Bronx, New York-10461, USA Tel: 718-430-2138; Fax: 718-430-8780; E-mail: dean.hosgood@einstein.yu.edu

Received March 30, 2016; Accepted May 04, 2016; Published May 07, 2016

Citation: Urman A, Josyula S, Rosenberg A, Lounsbury D, Rohan T, et al. (2016) Burden of Lung Cancer and Associated Risk Factors in Africa by Region. J Pulm Respir Med 6: 340. doi:10.4172/2161-105X.1000340

Copyright: @ 2016 Urman A, et al. This is an open-access article distributed under the terms of the Creative Commons Attribution License, which permits unrestricted use, distribution, and reproduction in any medium, provided the original author and source are credited. 
the lung cancer incidence and mortality rates for men, women and both men and women combined. Additionally, we extracted regional data on age-standardized mortality and incidence rates, as well as estimated incidence, mortality and 5-year prevalence for males, females and then for both sexes. Rates were standardize to the world population from 2012 as proposed by Segi et al. and modified by Doll et al. using 10 agegroups $\quad(0-14 ; 15-39 ; 40-44 ; 45-49 ; 50-54 ; 55-59 ; 60-64 ; 65-69 ; 70-74 ; 75+)$ $[8,9]$.

To explore the known etiologic risk factors for lung cancer among African populations, published studies were identified by a literature review. Peer-reviewed manuscripts published between 1969 and 2015 were identified by searching 'Pubmed' using keywords words related to lung cancer, risk factors, and geographic regions in Africa [("lung" OR "bronchi" OR bronchial OR bronchogenic OR "pulmonary" OR "respiratory system" OR "respiratory" AND "system" OR "respiratory" AND "tract" OR "respiratory tract" OR "trachea" OR "bronchus") AND ("algeria" OR "egypt" OR "libya" OR "morocco" OR "sudan" OR "tunisia" OR " western africa" OR "sahara" OR "burundi" OR "comoros" OR "djibouti" OR "eritrea" OR "ethiopia" OR "kenya" OR la reunion OR "madagascar" OR "malawi” OR "mauritius" OR "mozambique" OR "rwanda" OR "somalia" OR "tanzania" OR "uganda" OR "zambia" OR "zimbabwe" OR "angola" OR "cameroon" OR "central african republic" OR "chad" OR "democratic" AND "republic" OR "congo" OR "republic" AND "congo" OR "equatorial guinea" OR "gabon" OR "botswana" OR "lesotho" OR "namibia"OR "south" AND "Africa" OR "swaziland" OR "benin" OR "burkina faso" OR "cape verde" OR "cote divoire" OR "gambia" OR "ghana" OR "guinea-bissau"'guinea" OR”liberia” OR "mali” OR "mauritania” OR "niger” OR "nigeria” OR "senegal" OR "sierra leone" OR "togo" OR "south" AND "sudan") AND ("risk factors" OR ("risk" AND "factors") OR "etiology" OR "causality" OR "etiopathogenesis" OR "epidemiology")]. We restricted our search to the studies published in the English language and conducted on humans. In addition, we manually searched the references included in the articles that met our inclusion criteria.

The inclusion criteria for our study were: (i) epidemiological studies (case-control and cohort studies) and (ii) studies that examined the relationship between lung cancer in African regions or countries, their risk factors, incidence, and epidemiology. The initial keyword searches yielded 11,526 manuscripts of which 5,395 were selected for title review. Of these, 58 studies were reviewed for the abstract. Of those, 22 manuscripts were then reviewed and data were extracted on publication year, country or region in which the study was conducted, the lung cancer risk factors evaluated, exposure assessment method, odds ratio (OR) for each of the risk factors evaluated and 95\% confidence interval ( $95 \% \mathrm{CI})$. Figure 1 presents a brief summary of the studies which were chosen for review along with the respective exclusion criteria for the studies that were omitted.

\section{Results}

According to Globocon, the number of incidence lung cancer cases in Africa in 2012 was estimated to be 30,314, of which $72 \%$ were among males $(n=21,756)$ and $28 \%$ were among females $(n=8,558)$. The lung cancer incidence rates tended to be higher in males than in females for all African regions (Figure 2). The combined male and female incidence rates for Middle, Eastern, and Western Africa are lower than the combined male and female incidence rates in Southern and Northern Africa (Figure 2). The Southern region has the highest incidence rates for males and females of 26.1 and 10.2 respectively. Conversely, the Western region has the lowest IR in males (1.7 per 100,000) and Middle Africa for females (0.8 per 100,000).

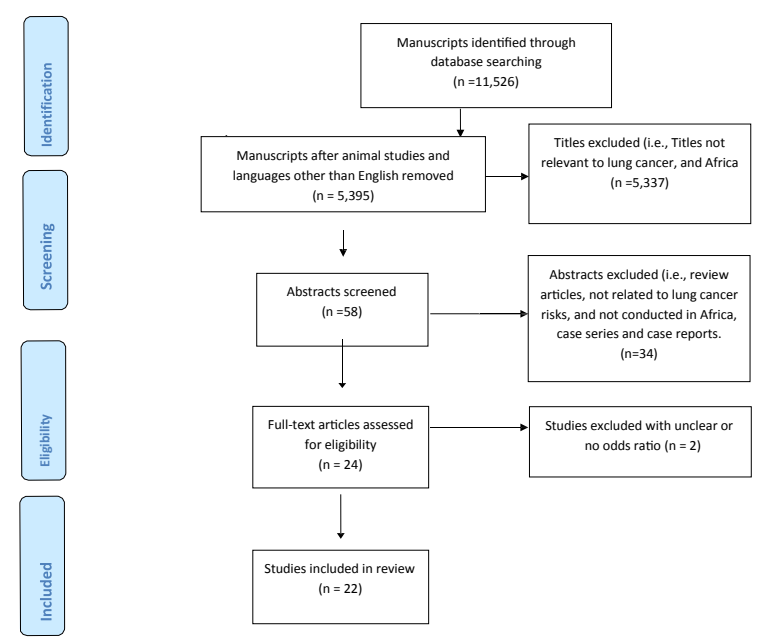

Figure 1: Flowchart illustrating literature review of articles related to lung cancer and risk factors in Africa.

When looking at the IRs by country, the lung cancer incidence rate was lowest among women (IR=0.0 per 100,000) in Comoros and Niger and lowest among men in Niger (IR=0.4 per 100,000) and Tanzania ( $I R=0.9$ per 100,000). The highest lung cancer incidence rates were in La France Reunion: 32.3 (per 100,000) among males and 11.2 (per $100,000)$ among females in South African Republic. South African Republic in Southern Africa had a rate of 18.5 (per 100,000) for both the sexes (Supplemental Table). Based on the large variation of lung cancer incidence rates among African regions, we attempted to identify and summarize the differing risk factors to potentially explain these discrepancies.

Table 1 summarizes the risk factors for lung cancer that have been studied in the various regions of Africa. Smoking was the most studied risk factor in each region. For example, significantly elevated risks were observed in a case-control study that included 118 incident lung cancer cases and 235 matched controls among current heavy smokers in Morocco (North Africa; OR=26.07; 95\% CI=6.58-103.27) [10]. Elevated risks for lung cancer were also observed in a cohort study that included 992 men and 290 women, which found that men in Zimbabwe smoking greater than $15 \mathrm{~g}$ of daily of tobacco were at an increased risk of developing lung cancer (East Africa; $\mathrm{OR}=5.2 ; 95 \% \mathrm{CI}=3.5-7.7$ ) [5]. A case-control study conducted on 78 South Africans with lung cancer compared to 386 South African controls found that those who smoked $21-30$ pack years $(\mathrm{OR}=5.7 ; 95 \% \mathrm{CI}=1.3-25.8)$ or more than 30 pack years $(\mathrm{OR}=13.2 ; 95 \% \mathrm{CI}=3.1-56.2)$ experienced increased risk of lung cancer [11]. In Sub-Saharan Africa, a cohort study, including 849 participants who had smoked daily in the past, found that men who smoked in the past for either $\leq 10$ pack-years or $>10$ pack-years had an increased risk of lung cancer [12].

Studies have also evaluated the risk of lung cancer from smoking cannabis. A case-control pooled analysis from three studies conducted in Tunisia, Morocco and Algeria on 430 male lung cancer patients compared to 788 male controls found an increased risk of lung cancer from smoking cannabis $(\mathrm{OR}=2.3$; 95\% $\mathrm{CI}=1.5-3.6)$ [13]. An increased risk of lung cancer from hashish/kiff and snuff exposures $(\mathrm{OR}=6.67$; 95\% CI=1.65-26.90), as well as exposures from passive or secondary smoke $(\mathrm{OR}=1.36 ; 95 \% \mathrm{CI}=0.71-2.62)$ were observed in a case-control 

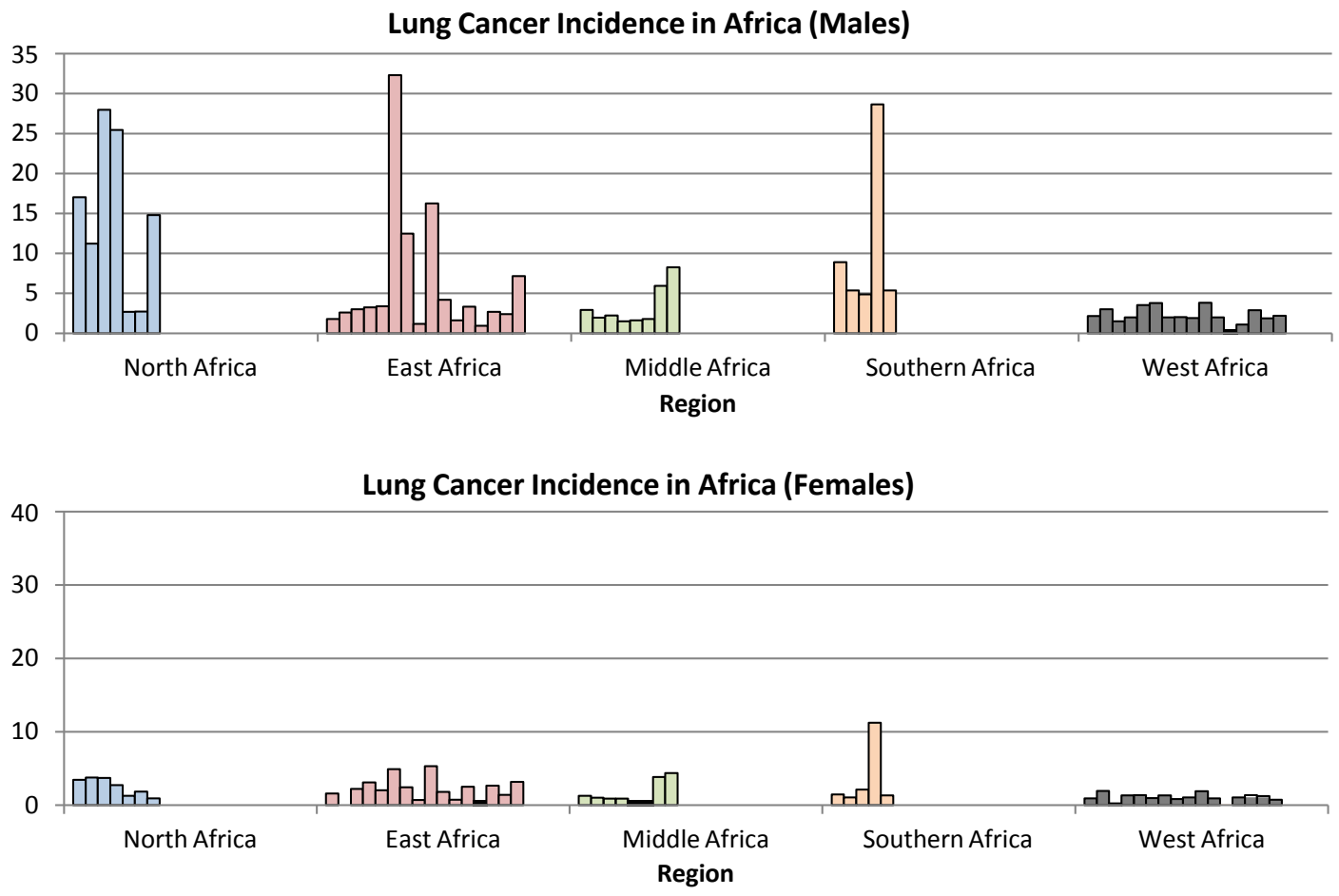

Lung Cancer Incidence in Africa (Males and Females)

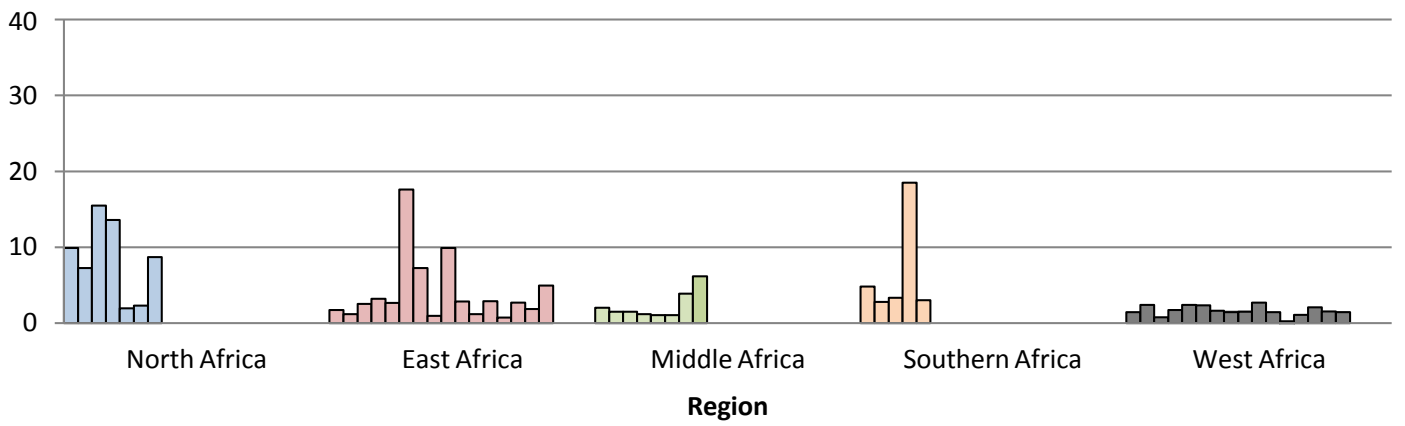

Lung Cancer Incidence in Africa Regions

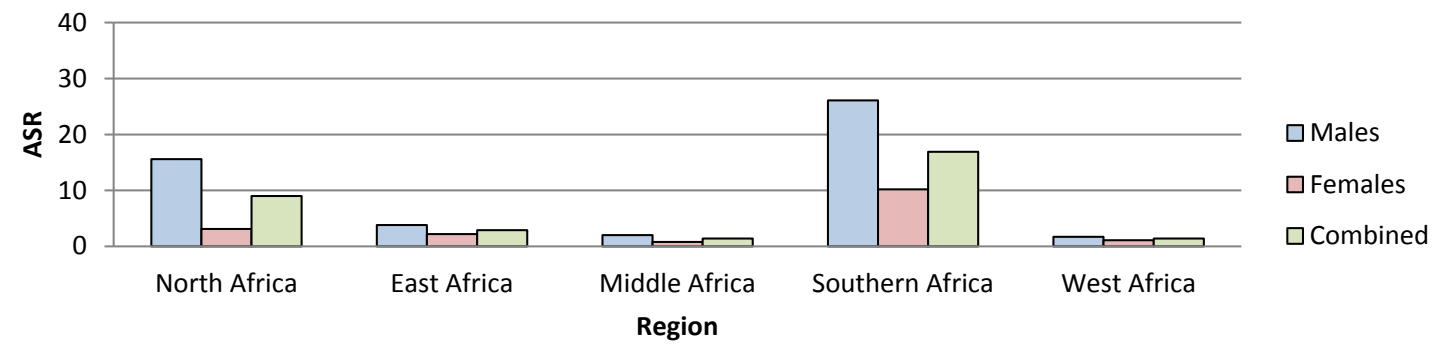

Figure 2: Lung cancer incidence rates in men, women, and combined population in African countries by region ${ }^{\dagger}$.

†Data from Globocan 2012

study that included 118 incident lung cancer cases and 235 matched controls in Casablanca, Morocco [10].

Beyond smoking exposures, studies evaluated occupational risk factors, such as silica and asbestos exposures, and working in mines and dusty environments. An OR of 1.75 (95\% CI=0.84-3.63) for occupational exposures (asbestos, iron, nickel, mining, silica, dusts, fumes, vapors, others) was observed in a case-control study that included 118 incident lung cancer cases and 235 matched controls in Morocco [10]. A case-control study conducted in Southern Africa, which interviewed 288 male and 60 female lung cancer patients and 
Citation: Urman A, Josyula S, Rosenberg A, Lounsbury D, Rohan T, et al. (2016) Burden of Lung Cancer and Associated Risk Factors in Africa by Region. J Pulm Respir Med 6: 340. doi:10.4172/2161-105X.1000340

\begin{tabular}{|c|c|c|c|c|}
\hline Risk Factor & Northern Africa & Southern Africa & Western Africa & Eastern Africa \\
\hline Tobacco Smoking & $\begin{array}{l}\text { Tobacco smoking: } \\
\text { OR: } 26.07 \\
\text { (95\% Cl 6.58-103.27) for current } \\
\text { heavy smokers [10] } \\
\text { Cannabis Smoking: } \\
\text { OR: } 2.3(95 \% \mathrm{Cl}=1.5 \text {-3.6) } \\
\text { among ever smokers after } \\
\text { controlled for tobacco [13] } \\
\text { Hashish/kiff and snuff: OR=6.67 } \\
(95 \% \mathrm{Cl}=1.65-26.90)[10] \\
\text { Passive smoking OR=1.36 } \\
(95 \% \mathrm{Cl}=0.71-2.62)[10]\end{array}$ & $\begin{array}{l}\text { Tobacco smoking: } \\
\text { ASR ratio=2.3 for men, 3.9 for } \\
\text { women in Sierra Leone [12] } \\
\text { ASR ratio=2.2 for men and } 6.1 \text { for } \\
\text { women in Swaziland [12] } \\
\text { RR }=5.7 \\
(95 \% \mathrm{Cl}=1.3-25.8) \\
\text { for } 21-30 \text { pack years [11] } \\
\mathrm{RR}=13.2 \\
(95 \% \mathrm{Cl}=3.1-56.2) \\
\text { for }>30 \text { pack years [11] } \\
\text { OR=12.0 (95\% } \mathrm{Cl}=6.5 \text { to } 22.3) \text { in } \\
\text { heavy smokers [14] }\end{array}$ & $\begin{array}{l}\text { Tobacco smoking: } \\
\text { ASR ratio=2.4 for men, } 5.0 \text { for } \\
\text { women in Benin [12] } \\
\text { ASR ratio=4.1 for men, } 22.5 \text { for } \\
\text { women in Niger [12] } \\
\text { OR=1.76 }(95 \% \mathrm{Cl}=1.22 \text { to } 2.54) \text { [16] }\end{array}$ & $\begin{array}{l}\text { Tobacco smoking: } \\
\text { ASR ratio=11.9 for men, } 33.5 \text { for } \\
\text { women in Malawi [12] } \\
\text { ASR ratio=3.3 for men, } 6.9 \text { for } \\
\text { women in Mozambique [12] } \\
\text { OR } 5.2(95 \% \mathrm{Cl} 3.5-7.7) \text { for men } \\
\text { in Zimbabwe smoking }>15 \mathrm{~g}[15] \\
\text { OR in tobacco farm workers=10.28 } \\
(95 \% \mathrm{Cl}=3.39-31.2)[17] \\
\text { OR=32.57 }(95 \% \mathrm{Cl}=6.05-175.25) \\
{[18]}\end{array}$ \\
\hline $\begin{array}{l}\text { Occupational Risk } \\
\text { Factors }\end{array}$ & $\begin{array}{l}\text { Asbestos: } \\
\text { Increase from } 0.47 \% \text { in } 2001, \\
\text { to } 1.4 \% \text { in } 2004 \text { in relative } \\
\text { frequency of malignant pleural } \\
\text { mesothelioma related to } \\
\text { Asbestos in Egypt [19] } \\
\text { Occupational Exposures: } \\
\text { OR=1.75(95\%Cl=0.84-3.63) [10] }\end{array}$ & $\begin{array}{l}\text { Asbestos: } \\
\mathrm{OR}=2.8(0.7-10.4) \text { among men and } \\
\mathrm{OR}=5.4(1.3-22.5) \text { among women } \\
\text { were asbestos was mined [14] } \\
\text { Silicosis: } \\
\mathrm{RR}=2.45 \\
(95 \% \mathrm{Cl} 1.2-5.2)[11] \\
\\
\text { Working in dusty conditions: } \\
\text { OR=3.2 }(95 \% \mathrm{Cl} 1.8-5.8) \text { for men } \\
\text { OR=0.5 }(95 \% \mathrm{Cl} 0.3-1.1) \text { for women } \\
{[14]}\end{array}$ & & $\begin{array}{l}\text { Working in mines: } \\
\text { OR=1.2 }(95 \% \mathrm{Cl}=0.9-1.4)[15] \\
\text { Asbestos: } \\
\text { OR=0.7 (95\% Cl=0.5-1.0) [15] } \\
\text { Chrome: } \\
\text { OR=1.1 (95\% Cl=0.7-1.7) [15] } \\
\text { Coal: } \\
\text { OR=1.1 (95\% Cl=0.8-1.6) [15] } \\
\text { Copper: } \\
\text { OR=1.5 (95\% Cl=1.0-2.2) [15] } \\
\text { Gold: } \\
\text { OR=1.5 (95\% Cl=0.9-2.3) [15] } \\
\text { Nickel: } \\
\text { OR=2.6 (95\% Cl=1.6-4.2) [15] } \\
\text { Arsenic: } \\
25 \text { of } 29 \text { lung cancer patients } \\
\text { worked in arsenic mines [20] }\end{array}$ \\
\hline $\begin{array}{l}\text { Environmental Risk } \\
\text { Factors }\end{array}$ & $\begin{array}{l}\text { Poor ventilation: OR=1.22 (95\% } \\
\mathrm{Cl}=0.57-2.58)[10]\end{array}$ & $\begin{array}{l}\text { Coal or wood burning in house: } \\
\text { RR=1.09 }(95 \% \mathrm{Cl} 1.94-3.47) \text { for } \\
\text { women [21] } \\
\text { Outdoor air pollution: } \\
R R=1.08(95 \% \mathrm{Cl}=1.01-1.10) \text { [22] }\end{array}$ & & \\
\hline Infection & $\begin{array}{l}\text { Chronic bronchitis n OR=4.16 } \\
(95 \% \mathrm{Cl}=1.76-9.85)[10]\end{array}$ & $\begin{array}{l}\text { HIV: } \\
\text { AOR=1.1 (95\% Cl 0.7-1.6) for HIV } 1 \\
\text { infection [23] }\end{array}$ & & $\begin{array}{l}\text { HIV: } \\
\text { SIR=5.0 (95\% CI 1.0-15.0) for } \\
\text { HIV-infected Individuals [10] }\end{array}$ \\
\hline $\begin{array}{l}\text { Genetic Susceptibility } \\
\text { [single nucleotide } \\
\text { polymorphisms (SNPs)] }\end{array}$ & $\begin{array}{l}\text { CYP1A2: -3860GNA, } \\
\text {-2467delT, -739TNG and } \\
\text {-163CNA in Tunisia [24] } \\
\text { CYP1A1 m1 and m2: In Egypt } \\
\text { [25] } \\
\text { CYP1A2-T2467delT (allele*1D): } \\
\text { In Tunisia [26] } \\
\text { IL-17A and 17F: -52 G/A, 7488 } \\
\text { A/G, 7383 A/G in Tunisia [27] } \\
\text { IL-8: (rs4073, rs2227306 } \\
\text { in Tunisia [28] } \\
\text { TNFa(-308 G/A, -38 G/A); TNF } \beta \\
\text { 252A > G in Tunisia [29] }\end{array}$ & & & \\
\hline
\end{tabular}

${ }^{+}$No studies were found to be conducted on Middle Africa.

Table 1: Risk factors associated with lung cancer in Africa, stratified by region ${ }^{\dagger}$.

183 male and 197 control patients, found that the OR for lung cancer was 2.1 (95\% CI=1.3-3.8) for current residents and 2.8 (95\% CI=1.55.4) for people born in asbestos polluted areas [14]. Studies were also conducted on the risk of developing lung cancer attributed to silicosis. For example, one case-control study conducted on 78 South Africans with lung cancer compared to 386 South African controls, reported an 
increased risk of lung cancer associated with the presence of silicosis $(\mathrm{OR}=2.45,95 \% \mathrm{CI}=1.2-5.2)$ [11]. Working in dusty environments in South Africa was associated with increased risk of lung cancer $(\mathrm{OR}=3.2$; 95\% CI=1.8-5.8) for men [14]. A study conducted from 1963-1972 featured 10,678 cases of malignant cancers that were registered in the cancer registry of Bulawayo, Zimbabwe. This study gave questionnaires to patients diagnosed with any cancer and assessed their risk factors for the cancers they developed. If patients were not able to be contacted, they spoke to their family members. This study did not demonstrate significant associations for occupation exposures from asbestos (OR=0.7; 95\% CI=0.5-1.0), chrome $(\mathrm{OR}=1.1 ; 95 \% \mathrm{CI}=0.7-1.7)$, coal $(\mathrm{OR}=1.1 ; 95 \% \mathrm{CI}=0.8-1.6)$, copper $(\mathrm{OR}=1.5 ; 95 \% \mathrm{CI}=1.0-2.2)$, gold $(\mathrm{OR}=1.5 ; 95 \% \mathrm{CI}=0.9-2.3)$, or working in mines $(\mathrm{OR}=1.2 ; 95 \% \mathrm{CI}=0.9$ 1.4); however, this may be due to the limited statistical power based on the number of lung cancer cases ( $n=121$ males, 6 females) in the registry [15]. Of note, the study did observe a statistically significant increased risk for lung cancer associated with occupational nickel exposures $(\mathrm{OR}=2.6 ; 95 \% \mathrm{CI}=1.6-4.2)$ [15].

For environmental risk factors, it was reported that in South Africa, coal or wood burning in the house was associated with a risk of lung cancer ( $\mathrm{RR}=2.0 ; 95 \% \mathrm{CI}=1.1-3.6)$ for men and women [14], whereas in another study, poor ventilation in kitchen was not associated with altered risk $(\mathrm{OR}=1.22 ; 95 \% \mathrm{CI}=0.57-2.58)[10]$.

A limited number of studies have explored the associations between infections and risk of lung cancer. Risk of lung cancer in association with a history of chronic bronchitis was found to be increased 4-fold $(\mathrm{OR}=4.16 ; 95 \% \mathrm{CI}=1.76-9.85)$ in a case-control study on 118 incident lung cancer cases and 235 age, sex and residence matched controls with malignant mesothelioma in Casablanca, Morocco [10]. This association may be explained by the strong association between smoking status and chronic bronchitis, with $97.4 \%$ of subjects with the disease having a history of smoking compared to $64.5 \%$ of those without chronic bronchitis having a history of smoking $(\mathrm{p}<0.0001)[10]$. There is also some evidence that HIV infection was associated with an OR of 1.1 (95\% CI $=0.7-1.6)$ [23] and a standardized incidence ratio $(\mathrm{SIR})=5.0$ (95\% CI=1.0-15.0).

Genetic susceptibility to lung cancer has been studied in Tunisia and Egypt, both in the Northern African region. While studies of genetic susceptibility and lung cancer risk in Africa are sparse, one of the most frequently observed associations is genetic variation in cytochrome $\mathrm{P}$ 450 (CYP) and risk of lung cancer. Such observations include that the CYP1A $1 \mathrm{~m} 1$ and $\mathrm{m} 2$ polymorphisms were associated with an increased risk of lung cancer $(\mathrm{OR}=1.7 ; 95 \% \mathrm{CI}=1.1-2.6 ; \mathrm{OR}=1.8 ; 95 \% \mathrm{CI}=1.2-2.8$, respectively), in a case-control study of 110 lung cancer cases and 110 controls [25]. Further, CYP1A2-3860G/A and -739T/G variation was associated with an increased risk of lung cancer $(\mathrm{OR}=6.0 ; 95 \% \mathrm{CI}=2.9$ 12.9; $\mathrm{OR}=3.0 ; 95 \% \mathrm{CI}=1.5-6.0$, respectively) [24], and CYP1A2-2467T/ delT variation was suggested to be associated with an risk of lung cancer $(\mathrm{OR}=2.0 ; 95 \% \mathrm{CI}=0.9-4.7)$ [26], in a case-control study of 101 lung cancer cases and 98 controls. The immune-pathogenesis of lung cancer has also been explored in studies of variations in Interleukins (IL) genes among African populations. In a case-control study of 239 lung cancer cases and 258 controls, variation in $I L-17 F-7488 \mathrm{~A} / \mathrm{G}$ was associated with a risk of lung cancer $(\mathrm{OR}=1.8 ; 95 \% \mathrm{CI}=1.0-3.2)$ [27]. IL-8 -251T/A was associated with NSCLC $(\mathrm{p}=0.004)$ in a case-control study of 170 cases and 225 controls [28].

\section{Discussion}

Due to the aging and growing world population, the global burden of cancer is increasing particularly due to the adoption of risky behaviours like smoking in developing countries [30]. Our literature review found that tobacco smoking and environmental exposures are associated with lung cancer risk in numerous regions of Africa. This elevated prevalence of these risk factors is of concern, for example, the prevalence of current moderate smoking in six sub-Saharan countries (Benin, Malawi, Mozambique, Niger, Sierra Leone, and Swaziland) ranges from $8.7 \%$ to $34.6 \%$ among males [12]. Further, the use of household solid fuels for cooking or heating is prevalent in roughly one-third of South African households [21]. Lung cancer is the most common cancer among males (23\% of all cancer-related deaths) and the third most common cancer among females in developing countries ( $11 \%$ of the total female cancer deaths) $[1,2,5]$. The high case fatality rate and the possibility of reducing the risk attributable to preventable exposures, such as tobacco smoke, infections, occupational and environmental exposures, through public health campaigns emphasizes the need to study lung cancer risk factors and their respective mitigation strategies in developing countries.

Globocan is a project that uses data from IACR (International Association of Cancer Registries) to provide cancer estimates on mortality, prevalence and incidence for 184 countries. An important finding from a previous publication using the Globocan [1] study was that the overall cancer incidence rates in the developing world were half of those seen in the developed world [5]. The reasons for the observed variation could be due to a lack of comprehensive data and reporting, poor diagnosis rates, and limited access to treatment [5]. Another important reason for the potential variability could be the difference between incidence rates and diagnosis rates. The cancer diagnosis rate in Africa is low, and when most cancers are finally detected it is at a late stage. It is therefore reasonable to suspect that there are many people who die of lung cancer without ever receiving a formal diagnosis or autopsy to prove their illness. Therefore, even though the literature and Globocan [7] rates, show lower lung cancer rates in Africa, than in other more developed countries, it is possible that the incidence rates are underestimates due to the aforementioned. Furthermore, there are limited resources for health research in Africa, which could also contribute to underreporting.

We summarized the state of knowledge pertaining to lung cancer risk in Africa by reviewing the Globocan database and conducting the literature review. We hypothesize that there may be a need for careful examination of data for a possible bias from underreporting. In addition, our literature review helped identify the seemingly clear gap that much of research in terms of the five main risk factor groups were conducted mainly in Northern and Southern Africa; relatively fewer studies were conducted in Eastern and Western Africa, and none in Central Africa.

This is one of the first studies to conduct a literature review and summarize the incidence rates of lung cancer according to the different regions in Africa. Even though we robustly reviewed the literature to identify attempt to identify all existing studies that evaluate the lung cancer and risk factor associations, there were only a limited number of studies available for analysis. Many studies should be interpreted with caution until they are replicated in larger studies with ample statistical power, particularly those evaluating the associations between genetic variation and lung cancer risk which need to account for multiple comparisons. Finally, there is an important research opportunity to extend our literature review, which only included articles published in English, to peer-reviewed manuscripts published in other languages. While lung cancer is the focus of this review, we also acknowledge that there are a number of other major causes of death that occur in Africa, such as prenatal and childhood mortality, ischemic heart disease, and cerebrovascular disease [31]. 
Citation: Urman A, Josyula S, Rosenberg A, Lounsbury D, Rohan T, et al. (2016) Burden of Lung Cancer and Associated Risk Factors in Africa by Region. J Pulm Respir Med 6: 340. doi:10.4172/2161-105X.1000340

Our review is a first step in helping researchers identify the differences in the lung cancer burden and associated risk factors by African region. Although it is beyond the scope of this review, the ultimate goal is to assist in the facilitation of public health solutions in geographic regions that identify lung cancer as a burden. There are many public health strategies that could be implemented, and some are already ongoing, to help lower the lung cancer rates in Africa. For instance, conducting anti-smoking education campaigns; reduction of outdoor air pollution; regulation of occupational exposures; and reducing indoor air pollution. Until we fully appreciate the attributable risk fractions of lung cancer for each risk factor in each region, however, policy makers may not be able to effectively target their limited resources to high impact prevention strategies.

\section{References}

1. Ferlay J, Shin HR, Bray F, Forman D, Mathers C, et al. (2010) Estimates of worldwide burden of cancer in 2008: GLOBOCAN 2008. Int J Cancer 127: 2893-2917.

2. Lozano R, Naghavi M, Foreman K, Lim S, Shibuya K, et al. (2012) Global and regional mortality from 235 causes of death for 20 age groups in 1990 and 2010: a systematic analysis for the Global Burden of Disease Study 2010. Lancet 380: 2095-2128.

3. Jemal A, Center MM, DeSantis C, Ward EM (2010) Global patterns of cancer incidence and mortality rates and trends. Cancer Epidemiol Biomarkers Prev 19: 1893-1907.

4. Sankaranarayanan $R$, Swaminathan $R$, Jayant $K$, Brenner $H$ (2011) An overview of cancer survival in Africa, Asia, the Caribbean and Central America: the case for investment in cancer health services. IARC Sci Publ: 257-291.

5. Lam WK, White NW, Chan-Yeung MM (2004) Lung cancer epidemiology and risk factors in Asia and Africa. Int J Tuberc Lung Dis 8: 1045-1057.

6. Parkash J, Younis MZ, Ward W (2015) Healthcare for the Ageing Populations of Countries of Middle East and North Africa. Ageing International 40: 3-12.

7. Tao Z, Shi A, Lu C, Song T, Zhang Z, et al. (2014) Breast Cancer: Epidemiology and Etiology. Cell Biochem Biophys.

8. Doll RPP, Waterhouse JAH (1966) Cancer Incidence in Five Continents. Geneva: Union Internationale Contre le Cancer: 1.

9. (1960) MS: Cancer Mortality for Selected Sites in 24 Countries (1950-57) Department of Public Health, Tohoku University of Medicine, Sendai, Japan.

10. Sasco AJ, Merrill RM, Dari I, Benhaïm-Luzon V, Carriot F, et al. (2002) A casecontrol study of lung cancer in Casablanca, Morocco. Cancer Causes Control 13: $609-616$

11. Hnizdo E, Murray J, Klempman S (1997) Lung cancer in relation to exposure to silica dust, silicosis and uranium production in South African gold miners. Thorax 52: 271-275.

12. Winkler V, Ott JJ, Cowan M, Becher H (2013) Smoking prevalence and its impacts on lung cancer mortality in Sub-Saharan Africa: An epidemiological study. Prev Med 57: 634-640.

13. Berthiller J, Straif K, Boniol M, Voirin N, Benhaïm-Luzon V, et al. (2008) Cannabis smoking and risk of lung cancer in men: a pooled analysis of three studies in Maghreb. J Thorac Oncol 3: 1398-1403.

14. Mzileni O, Sitas F, Steyn K, Carrara H, Bekker P (1999) Lung cancer, tobacco, and environmental factors in the African population of the Northern Province, South Africa. Tob Control 8: 398-401.

15. Parkin D, Vizcaino A, Skinner M, Ndhlovu A (1194) Cancer patterns and risk factors in the African population of southwestern Zimbabwe, 1963-1977. Cancer Epidemiol Biomarkers Prev 3: 537-547.

16. Okeh UM (2009) Statistical measure of association between smoking and lung cancer in Abakaliki, Ebonyi State Nigeria. East Afr J Public Health 6 Suppl: 23-29.

17. Kusemamariwo T, Neill $P$ (1990) Carcinoma of the bronchus in tobacco farm workers. An unrecognised high risk group. Trop Geogr Med 42: 261-264.

18. Gelfand M, Graham AJ, Lightman E (1968) Carcinoma of bronchus and the smoking habit in Rhodesian Africans. Br Med J 3: 468-469.

19. Gaafar RM, Eldin NH (2005) Epidemic of mesothelioma in Egypt. Lung Cancer 49: S17-S20.

20. Osburn HS (1969) Lung cancer in a mining district in Rhodesia. S Afr Med J 43: $1307-1312$

21. Norman R, Barnes B, Mathee A, Bradshaw D, Collaboration SACRA (2007) Estimating the burden of disease attributable to indoor air pollution from household use of solid fuels in South Africa in 2000. S Afr Med J 97: 764-771.

22. Norman R, Cairncross E, Witi J, Bradshaw D; South African Comparative Risk Assessment Collaborating Group (2007) Estimating the burden of disease attributable to urban outdoor air pollution in South Africa in 2000. S Afr Med J 97: 782-790.

23. Stein L, Urban MI, O'Connell D, Yu XQ, Beral V, et al. (2008) The spectrum of human immunodeficiency virus-associated cancers in a South African black population: Results from a case-control study, 1995-2004. Int J Cancer 122 2260-2265.

24. B'chir F, Pavanello S, Knani J, Boughattas S, Arnaud MJ, et al. (2009) CYP1A2 genetic polymorphisms and adenocarcinoma lung cancer risk in the Tunisian population. Life Sci 84: 779-784.

25. Hussein AG, Pasha HF, El-Shahat HM, Gad DM, Toam MM (2014) CYP1A1 gene polymorphisms and smoking status as modifier factors for lung cancer risk. Gene 541: 26-30.

26. Pavanello S, B'chir F, Pulliero A, Saguem S, Ben Fraj R, et al. (2007) Interaction between CYP1A2-T2467DELT polymorphism and smoking in adenocarcinoma and squamous cell carcinoma of the lung. Lung Cancer 57: 266-272.

27. Kaabachi W, Ben Amor A, Kaabachi S, Rafrafi A, Tizaoui K, et al. (2014) Interleukin-17A and -17F genes polymorphisms in lung cancer. Cytokine 66 23-29

28. Rafrafi A, Chahed B, Kaabachi S, Kaabachi W, Maalmi H, et al. (2013) Association of IL-8 gene polymorphisms with non small cell lung cancer in Tunisia: A case control study. Hum Immunol 74: 1368-1374.

29. Kaabachi S, Kaabachi W, Rafrafi A, Belkis H, Hamzaoui K, et al. (2013) Tumo necrosis factor gene polymorphisms in Tunisian patients with non-small cell lung cancer. Clin Lab 59: 1389-1395.

30. Torre LA, Siegel RL, Ward EM, Jemal A (2016) Global Cancer Incidence and Mortality Rates and Trends--An Update. Cancer Epidemiol Biomarkers Prev 25: 16-27.

31. Kassebaum NJ, Bertozzi-Villa A, Coggeshall MS, Shackelford KA, Steiner C, et al. (2014) Global, regional, and national levels and causes of maternal mortality during 1990-2013: a systematic analysis for the Global Burden of Disease Study 2013. Lancet 384: 980-1004 